\title{
$\mathrm{Ni} / \mathrm{Cu}$ 금속전극 태양전지의 $\mathrm{Ni}$ electroless plating에 관한 연구
}

\author{
이재두 ${ }^{1}$, 김민정 ${ }^{1}$, 권혁용 $^{1}$, 이수홍 ${ }^{1, a}$ \\ 1 세종대학교 전자공학과
}

\section{The Research of Ni Electroless Plating for Ni/Cu Front Metal Solar Cells}

\author{
Jae-Doo Lee ${ }^{1}$, Min-Jeong Kim ${ }^{1}$, Min-Jeong Kim ${ }^{1}$, and Soo-Hong Lee ${ }^{1, a}$ \\ ${ }^{1}$ Department of Electronics Engineering, Sejong University, Seoul 143-747, Korea
}

(Received January 17, 2011; Revised February 18, 2011; Accepted February 22, 2011)

\begin{abstract}
The formation of front metal contact silicon solar cells is required for low cost, low contact resistance to silicon surface. One of the front metal contacts is $\mathrm{Ni} / \mathrm{Cu}$ plating that it is available to simply and inexpensive production to apply mass production. $\mathrm{Ni}$ is shown to be a suitable barrier to $\mathrm{Cu}$ diffusion into the silicon. The process of $\mathrm{Ni}$ electroless plating on front silicon surface is performed using a chemical bath. Additives and buffer agents such as ammonium chloride is added to maintain the stability and $\mathrm{pH}$ control of the bath. $\mathrm{Ni}$ deposition rate is found to vary with temperature, time, utilization of bath. The experimental result shown that Ni layer by SEM (scanning electron microscopy) and EDX analysis. Finally, plated $\mathrm{Ni} / \mathrm{Cu}$ contact solar cell result in an efficiency of $17.69 \%$ on $2 \times 2 \mathrm{~cm}^{2}, \mathrm{Cz}$ wafer.
\end{abstract}

Keywords: Silicon solar cells, Ni/Cu front metal, $\mathrm{Ni}$ electroless plating, $\mathrm{Cu}$ electroplating

\section{1. 서 론}

현재 결정질 실리콘 태양전지 시장의 대부분을 차지하 고 있는 스크린 프린팅 태양전지는 전극 형성이 용이하 고 대량 생산이 가능한 장점을 지니고 있다. 하지만 전면 전극 형성 물질인 $\mathrm{Ag}$ paste는 순수한 은 성분이 아닌 glass frit 성분을 함유하고 있어 열처리 공정 후 전기 전 도도가 일반 순수 $\mathrm{Ag}$ 에 비해 약 $1 / 3$ 로 떨어지는 현상이 있다. 이런 단점을 보완하기 위해 전면 전극 형성에 있어 서 plating을 이용한 $\mathrm{Ni} / \mathrm{Cu}$ 금속전극을 형성하게 되면 $\mathrm{Ag}$ paste에 비해 저렴한 가격과 실리콘 기판과 전극 사 이의 낮은 접촉 저항으로 인한 높은 효율을 달성할 수 있다[1,2]. 전극으로 사용되는 $\mathrm{Ni}$ 은 $\mathrm{Cu}$ 와 실리콘의 접촉 을 막아주는 diffusion barrier 역할을 할 뿐만 아니라 열 처리로 형성되는 $\mathrm{Ni}$ silicide를 이용하여 실리콘 기판과의 기계적 전기적 특성을 향상시켜준다. $\mathrm{Ni}$ silicide는 $\mathrm{Ni}_{2} \mathrm{Si}$

\footnotetext{
a. Corresponding author; shl@sejong.ac.kr
}

$\left(200 \sim 300^{\circ} \mathrm{C}\right), \mathrm{NiSi}\left(300 \sim 700^{\circ} \mathrm{C}\right), \mathrm{NiSi}_{2}\left(700 \sim 900^{\circ} \mathrm{C}\right)$ 의 각각의 열처리 온도에 따라 순차적으로 변화한다. 열처리 온도의 따라 각각 $\mathrm{Ni}_{2} \mathrm{Si}$ 는 약 $24 \mu \mathrm{\mu} \cdot \mathrm{cm}, \mathrm{NiSi}$ 는 약 $14 \mu$ $\Omega \cdot \mathrm{cm}, \mathrm{NiSi}_{2}$ 는 약 $50 \mu \Omega \cdot \mathrm{cm}$ 의 비저항을 가진다 $[3,4]$. 이 처럼 태양전지에 적용하기 위해 접촉저항이 낮은 $\mathrm{NiSi}$ $(14 \mu \Omega \cdot \mathrm{cm})$ 을 사용하는데 이는 전극과 실리콘 기판간의 접촉저항을 낮추어 주어 결과적으로 직렬저항을 감소시 켜 태양전지의 효율을 향상시킬 수 있다 [5].

이번 실험에서는 $\mathrm{Ni}$ 을 $\mathrm{Cu}$ 의 seed layer로 사용하기 위 하여 무전해 도금 법을 이용하여 온도에 따른 $\mathrm{Ni}$ 의 두께 와 이를 이용하여 $\mathrm{Ni} / \mathrm{Cu}$ 금속 전극 태양전지를 만들어 보았다.

\section{2. 실험 방법}

본 실험은 boron으로 doping된 p-type wafer, 비저항 


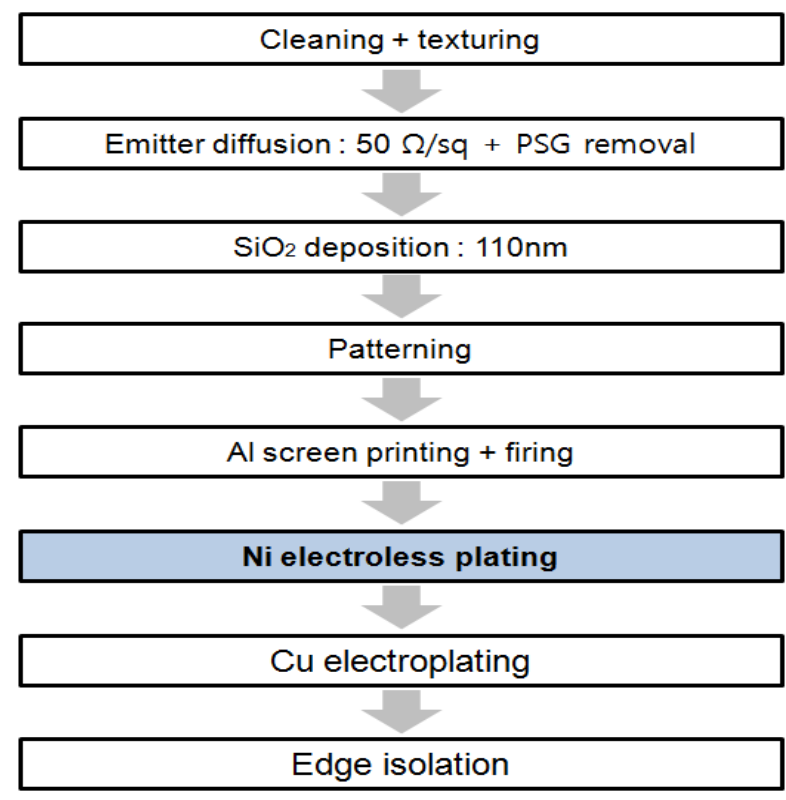

Fig. 1. Flow chart.

0.5 3.0 $\Omega \cdot \mathrm{cm}$, 두께는 $200 \mu \mathrm{m}$ 를 가진 $\mathrm{Cz}$ wafer를 사 용하였다. 실험 공정 순서는 다음 그림 1 과 같다.

우선 표면의 반사율을 낮추기 위해 $\mathrm{DI}: \mathrm{KOH}$ : IPA 의 적당한 용액 비율로 random pyramid를 형성 하였고, 잔류 solution 및 불순물을 제거하기 위해서 RCA cleaning을 하였다. Emitter 형성하기 위해 conventional tube furnace에서 $\mathrm{POCl}_{3}$ liquid source를 이용하여 면저항 약 $50 \Omega / \mathrm{sq}$ 를 형성하였다. Diluted HF 를 이용하여 diffusion 공정 중에 생긴 PSG(Phosphorus silicate glass)를 제거한 후 thermal oxidation furnace 를 이용하여 약 $110 \mathrm{~nm}$ 의 산화막을 형성하였으며, 후 면의 $\mathrm{Al}$ paste를 이용하여 screen printing을 한 후 열처리를 통해 후면 전극을 형성하였다. $\mathrm{Ni}$ 을 무전해 로 도금하는데 있어서 solution의 온도에 따라 실험을 진행하였으며, 최종적으로 $\mathrm{Cu}$ 를 전해 도금하여 solar simulator를 이용한 태양전지의 $\mathrm{I}-\mathrm{V}$ curve를 측정하 였다.

\section{3. 결과 및 고찰}

\section{1 $\mathrm{Ni}$ electroless plating}

실험에서는 전면전극으로 사용되어지는 $\mathrm{Ag}$ paste
Table 1. Ni electroless plating solution.

\begin{tabular}{c|c}
\hline Nickel chloride & $30 \mathrm{~g} / \ell$ \\
\hline Sodium hypophosphite & $28 \mathrm{~g} / \ell$ \\
\hline Triammonium & $65.8 \mathrm{~g} / \ell$ \\
\hline Ammonium chloride & $58.0 \mathrm{~g} / \ell$ \\
\hline
\end{tabular}

Table 2. Thickness of plated $\mathrm{Ni}$ layer according to temperature change.

\begin{tabular}{c|c}
\hline Temperature $\left({ }^{\circ} \mathrm{C}\right)$ & $\begin{array}{c}\text { Thickness of } \mathrm{Ni} \\
\text { layer }(\mu \mathrm{m})\end{array}$ \\
\hline \hline $80^{\circ} \mathrm{C}$ & $0.248 \mu \mathrm{m}$ \\
\hline $82^{\circ} \mathrm{C}$ & $0.832 \mu \mathrm{m}$ \\
\hline $85^{\circ} \mathrm{C}$ & $1.482 \mu \mathrm{m}$ \\
\hline $88^{\circ} \mathrm{C}$ & $1.618 \mu \mathrm{m}$ \\
\hline $90^{\circ} \mathrm{C}$ & $1.792 \mu \mathrm{m}$ \\
\hline
\end{tabular}

를 대신하여 도금 법을 이용한 $\mathrm{Ni} / \mathrm{Cu}$ 금속전극을 사 용하였다. 우선 $\mathrm{Cu}$ 는 $\mathrm{Ag}$ 다음으로 전기전도도가 우 수하며, 가격도 저렴하기 때문에 반도체 시장 전반적 으로 쉽게 널리 사용되어지고 있다. 하지만 $\mathrm{Cu}$ 금속 은 $\mathrm{Si}$ 내부로 침투하여 $\mathrm{pn}$ junction 근처에서 누설 전 류를 증가시키는 원인이 된다 [6]. Ni은 $\mathrm{Cu}$ 가 silicon 내부로 침투하는 것을 방지해 주는 diffusion barrier 역할을 할 뿐만 아니라 $\mathrm{Ni}$ silicide를 형성하여 금속과 기판간의 접촉저항을 낮추어 준다.

무전해 도금으로 $\mathrm{Ni}$ 을 형성하는 방법은 산화·환원 반응을 이용하는 것으로 환원제의 산화반응에 의해 금속이온이 환원되어 기판위에 석출되는 것으로 실리 콘 표면에 $\mathrm{Ni}$ 도금막을 형성되는 과정은 다음과 같 다.

$$
\begin{gathered}
\mathrm{H}_{2} \mathrm{PO}_{2}^{-}+\mathrm{H}_{2} \mathrm{O} \rightarrow \mathrm{HPO}_{3}^{2-}+2 \mathrm{H}^{+}+\mathrm{H}^{-} \\
2 \mathrm{H}^{-}+\mathrm{Ni}^{2+} \rightarrow \mathrm{Ni}+\mathrm{H}_{2} \\
-2 \mathrm{H}_{2} \mathrm{PO}_{2}^{-}+2 \mathrm{H}_{2} \mathrm{O}+\mathrm{Ni}^{2+} \rightarrow \mathrm{Ni}+\mathrm{H}_{2}+4 \mathrm{H}^{+}+2 \mathrm{HPO}_{3}^{2-}
\end{gathered}
$$

$\mathrm{Ni}$ solution 중에 $\mathrm{NiCl}_{2}$ (nickel chloride)를 주성분으 로 하고 $\mathrm{NaH}_{2} \mathrm{PO}_{2}$ (sodium hypophosphite)를 환원제로 사용하였으며, 또한 완충제 역할의 tri-ammonium citrate 


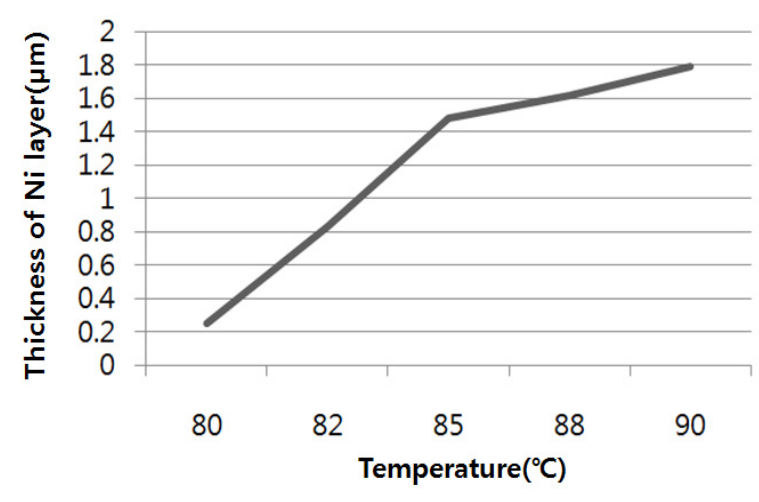

Fig. 2. Thickness of plated $\mathrm{Ni}$ layer according to temperature change.

와 $\mathrm{pH}$ 조절을 위해 ammonium chloride를 첨가하여 $\mathrm{pH}$ 8.5 8.7을 유지한 상태에서 실험을 진행하였다.

본 실험에서 사용되어진 $\mathrm{Ni}$ 무전해도금 solution조 성비는 표 1 과 같다

표 2 와 그림 2 는 시간을 일정하게 $2 \mathrm{~min}$ 으로 고정 시키고 $\mathrm{Ni}$ solution bath 온도에 따른 $\mathrm{Ni}$ 막의 두께 변화를 나타낸 것이다. $80^{\circ} \mathrm{C}$ 이하의 온도에서는 낮은 온도의 따른 $\mathrm{Ni}$ 의 도금시간을 늘려야 하지만 장시간 도금은 solution bath의 ammonium가 증발하게 되어 증착 rate가 점차 떨어져 $\mathrm{Ni}$ 이 기판 표면에 고르게 형성되지 않게 된다, 또한 $88^{\circ} \mathrm{C}$ 이상에서는 solution bath에 ammonium의 증발로 인해 $\mathrm{pH}$ 조절이 어려웠 으며 도금된 후 $\mathrm{Ni}$ 막의 벗겨지는 현상을 보였다. 실 험을 통해 $85^{\circ} \mathrm{C}$ 에서 $2 \mathrm{~min}, \mathrm{pH} 8.5 \sim 8.7$ 이었을 때 $\mathrm{Ni}$ 막이 고르게 도금되고 다음 공정으로 이어지는 $\mathrm{Ni}$ silicide sintering 공정과 $\mathrm{Cu}$ electroplating 공정에서 도 벗겨지는 현상이 없이 고르게 형성되어 적절한 온 도와 시간으로 여겨진다.

\section{$3.2 \mathrm{Ni}$ sintering}

$\mathrm{Ni}$ silicide를 형성하기 위해 RTP (rapid thermal process)를 이용하여 외부 공기와의 접촉을 최소화하 여 진행하였다. Sintering 공정에 있어서 시간이 너무 길거나 온도가 너무 높으면 $\mathrm{Ni}$ 이 $\mathrm{Si}$ 안으로 확산되어 들어가 pn junction 부근에서 shunting path되어 cell 의 $\mathrm{Voc}$ 를 낮추는 역할을 하고, sintering 시간이 너무 짧거나 온도가 너무 낮으면 접촉저항이 커져서 전지
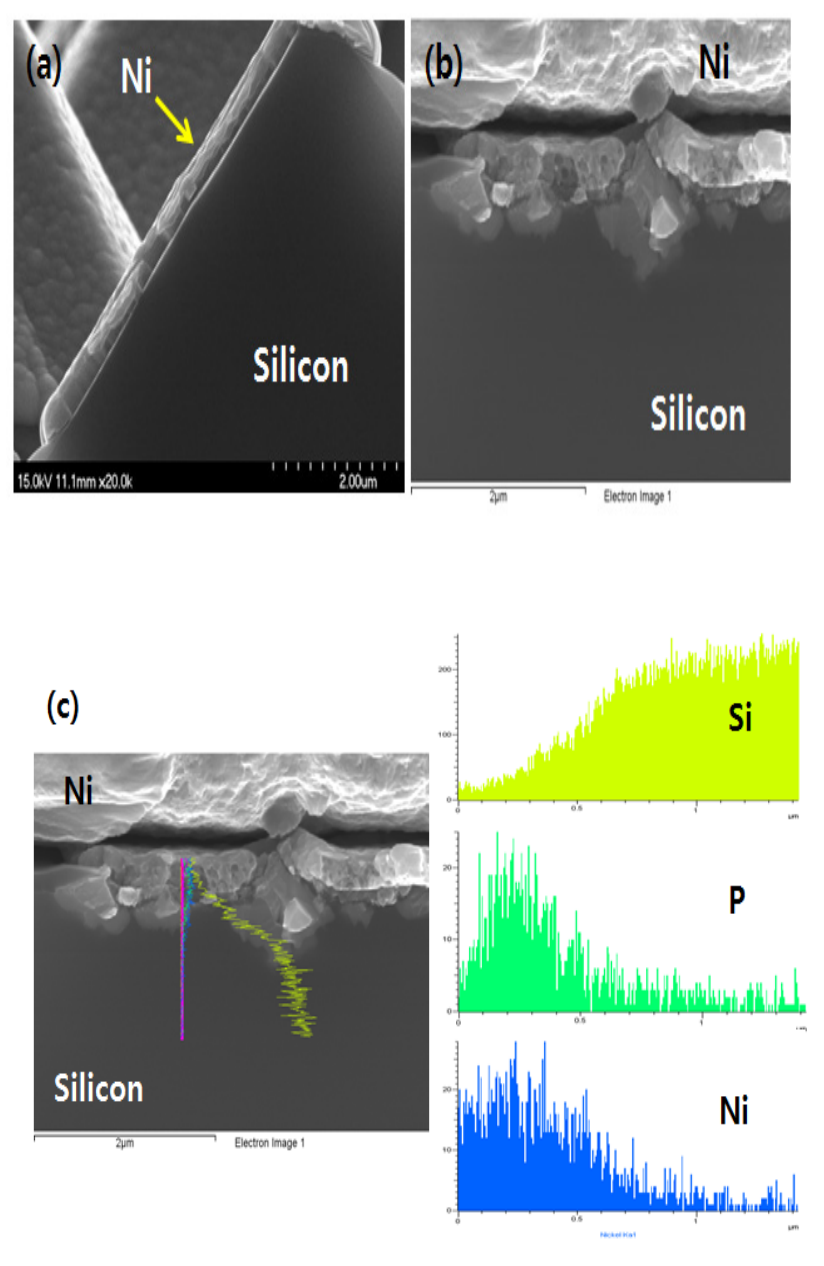

Fig. 3. SEM images of plated $\mathrm{Ni}$ layer (a) plated $\mathrm{Ni}$ layer before sintering (b) $\mathrm{Ni}$ silicide after sintering at 39 $0^{\circ} \mathrm{C}$ for $10 \mathrm{~min}$ (c) shows $\mathrm{EDX}$ analysis of plated $\mathrm{Ni}$ layer after sintering at $390^{\circ} \mathrm{C}$ for $10 \mathrm{~min}$.

의 $\mathrm{FF}$ (fill factor)을 낮추는 원인이 된다. 실험에서는 $390^{\circ} \mathrm{C}$ 에서 10 분간 진행하였을 때 cell의 변환 효율이 가 장 좋게 나타내었다.

그림 3에서는 $\mathrm{Ni}$ 전극의 $\mathrm{SEM}$ image와 $\mathrm{EDX}$. (energy dispersive X-ray spectroscopy) 성분 분석으로 $\mathrm{Ni}$ silicide가 형성된 것을 확인할 수 있다.

그림 3의 (a) SEM image에서는 electroless plating을 이용하여 Ni layer를 형성하였고, (b)에서는 sintering 공 정을 통해 $\mathrm{Ni}$ silicide를 형성하여 $\mathrm{Cu}$ 가 $\mathrm{Si}$ 으로 확산되는 것을 막아주는 barrier 역할을 해 주는 seed layer를 형 성된 것을 알 수 있다. 


\subsection{Cu electroplating}

$\mathrm{Cu}$ 의 전해 도금에는 황산구리 $\left(\mathrm{CuSO}_{4} \cdot 5 \mathrm{H}_{2} \mathrm{O}\right)$ 와 황산 $\left(\mathrm{H}_{2} \mathrm{SO}_{4}\right)$ 로 이루어져 있다. 황산의 주요 역할은 도 금액의 전도도를 향상시킴으로써 전류밀도를 낮은 전 압에서 얻고자 하는데 있다. 실험에서는 $200 \mathrm{~mA} / \mathrm{cm}^{2}$ 의 전류밀도에서 15 분간 진행하였으며, $\mathrm{Ni}$ seed layer 가 형성된 기판을 음극에, $\mathrm{Cu}$ plate를 양극에 걸어 도 금액에 담근 후 전류를 흘려주면 $\mathrm{Ni}$ 이 형성된 부분에 $\mathrm{Cu}$ 전극이 형성된다.

$\mathrm{Ni}$ electroless plating을 적용한 $\mathrm{Ni} / \mathrm{Cu}$ 금속 전극 태양전지를 제작하기 위해서 약 $50 \Omega / \mathrm{sq}$ 면저항과 $\mathrm{ARC}$ 와 passivation을 위한 약 $110 \mathrm{~nm}$ 의 $\mathrm{SiO}_{2}$ 층을 증착하였고, 또한 후면을 $\mathrm{Al}$ paste를 통하여 screen printing 한 후 $850^{\circ} \mathrm{C}$ 에서 $1 \mathrm{~min}$ 간 firing 하여 후면 전극을 형성하였다.

실험에서는 전면 전극으로 $\mathrm{Ni}$ 을 electroless plating 하여 그림 2 와 3 과 같이 시간을 $2 \mathrm{~min}$ 으로 일정하게 고정시키고 온도에 따른 $\mathrm{Ni}$ layer의 두께를 확인하였 다. 실험에서의 $\mathrm{Ni}$ layer는 $85^{\circ} \mathrm{C} 2 \mathrm{~min}$ 간 진행하였 을 때 약 $1 \mu \mathrm{m}$ 의 두께를 일정하게 형성하였고, silicide 형성을 위한 sintering 공정에서도 $390^{\circ} \mathrm{C} 10$ min간 진행하였을 때 shunting path가 일어나지 않으 며 가장 좋은 변화효율을 나타내었다.

그림 4 는 $\mathrm{Cu}$ 를 electroplating을 통해 형성한 전극 의 단면 SEM image 이다. Ni silicide가 형성된 seed layer위에 $\mathrm{Cu}$ 전극을 도금하였고, 최종적인 전극의 선폭은 두께 약 $22.0 \mu \mathrm{m}$, 폭 약 $43.4 \mu \mathrm{m}$ 로 형성하였다. 그림 4 에서 $\mathrm{Ni}$ 과 $\mathrm{Si}$ 사이의 분리가 일어나는 현상을 볼 수 있는데 전극 단면을 관찰하기 위해 절단할 때 물리적인 충격에 의한 현상으로 판단된다.

그림 5 는 $\mathrm{Ni} / \mathrm{Cu}$ 전극을 형성된 태양전지의 $\mathrm{I}-\mathrm{V}$ 특 성 곡선으로 $4 \mathrm{~cm}^{2}$ 의 면적에서 $\mathrm{Isc}=0.154 \mathrm{~A}, \mathrm{Voc}=$ $0.609 \mathrm{~V}, \mathrm{FF}=75.5 \%$, Efficiency $(\mathrm{Eff})=17.69 \%$ 의 태양 전지를 제작하였다.

\section{4. 결 론}

본 논문에서는 상업용으로 사용되어지고 있는 결정 질 실리콘 태양전지의 전극 형성 방법에서 기존의 Ag paste를 이용한 screen printing 법이 아닌 plating 을 이용하여 $\mathrm{Ni} / \mathrm{Cu}$ 를 형성하여 태양전지를 제작해 보았다. Ni layer를 형성하는데 무전해 도금법을 이용

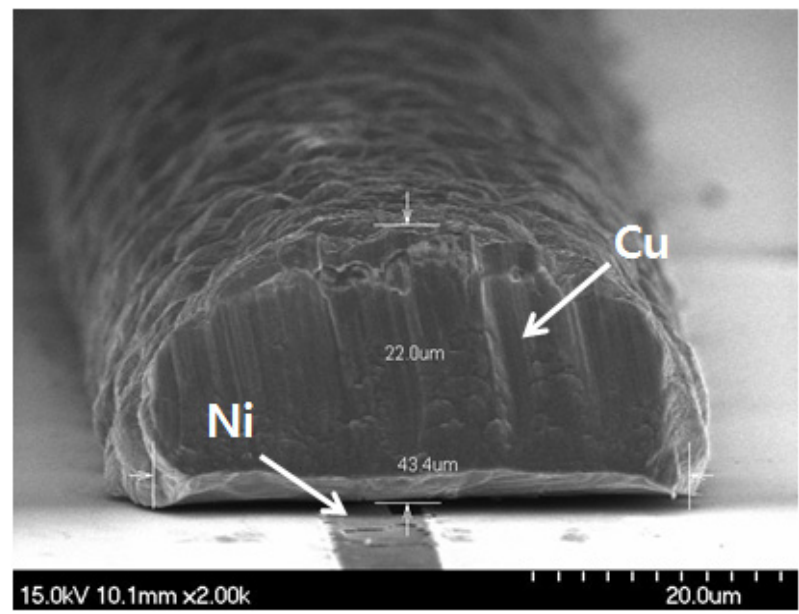

Fig. 4. SEM image of plated $\mathrm{Ni} / \mathrm{Cu}$ solar cell.

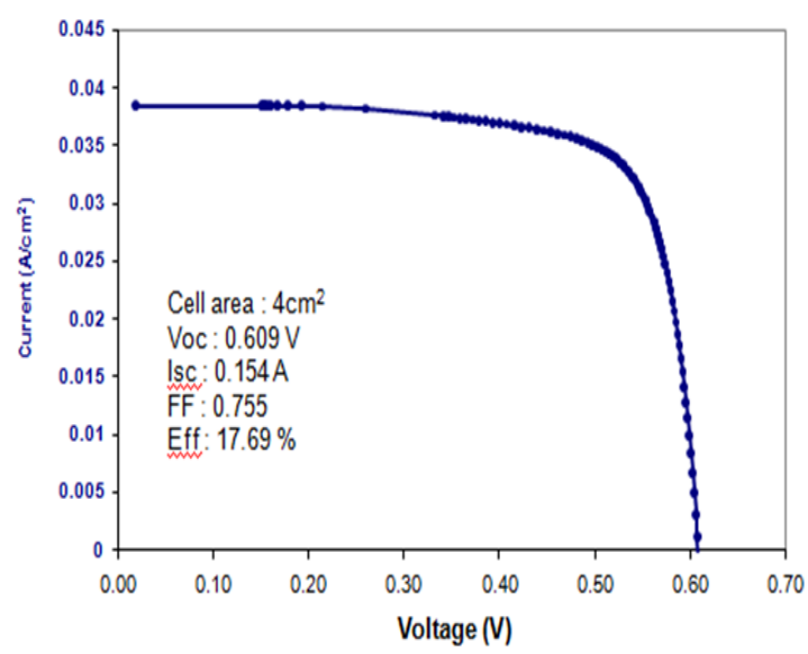

Fig. 5. Plated $\mathrm{Ni} / \mathrm{Cu}$ solar cell $\mathrm{I}-\mathrm{V}$ curve.

하였고 온도의 변화에 따라 $\mathrm{Ni}$ 막의 두께를 확인할 수 있었다. Ni이 얇게 형성되거나 혹은 두껍게 형성되 었을 때 후공정에 벗겨지는 형성이 있었으며, 이는 전체 태양전지를 제작하는데 있어서 전후 공정에 적 절한 $\mathrm{Ni}$ layer의 두께와 $\mathrm{Ni}$ silicide의 온도가 절대적 으로 필요하다는 것을 알 수 있었다. 실험을 통해 plated $\mathrm{Ni} / \mathrm{Cu}$ 금속 전면전극을 이용하여 $17.69 \%$ 태 양전지를 제작하였다.

하지만 도금된 $\mathrm{Cu}$ 전극의 두께가 선폭에 비해 높 이가 낮아 aspect ratio가 낮음을 알 수 있었다. 이런 원인을 보완하기 위해 적절한 $\mathrm{Ni}$ silicide 형성 온도와 시간을 찾고 높은 aspect ratio를 갖는 $\mathrm{Cu}$ 막을 형성 
하는 것이 변화 효율을 높이기 위한 연구라고 본다.

\section{감사의 글}

본 과제(결과물)는 지식경제부의 지원으로 수행한 에너지자원인력양성사업의 연구결과입니다.

\section{REFERENCES}

[1] Martin A. Green, Silicon Solar Cells : Advanced principles practice, Centre for Photovoltaic Devices and Systems, (University of New South Wales, sydney, 1995) p. 12.
[2] E. J .Lee, D. S. Kim, S. H. Lee, Sol. Energ. Mat. Sol. C, 74, 65 (2002).

[3] E. Colgan, M. Maenpaa, M. Finetti and MA. Nicolet, J. Electron. Mater, 12, 413 (1983).

[4] Y. Hu, S. P. Tay, J. Vac. Sci. Technol. A, 16 (1998).

[5] D. K. Schroder, IEEE Trans. Electron Devices, 31, 647 (1984).

[6] A. G. Milnes, Deep impurities in semiconductors, (Wiley, New York, 1973) p. 54. 